
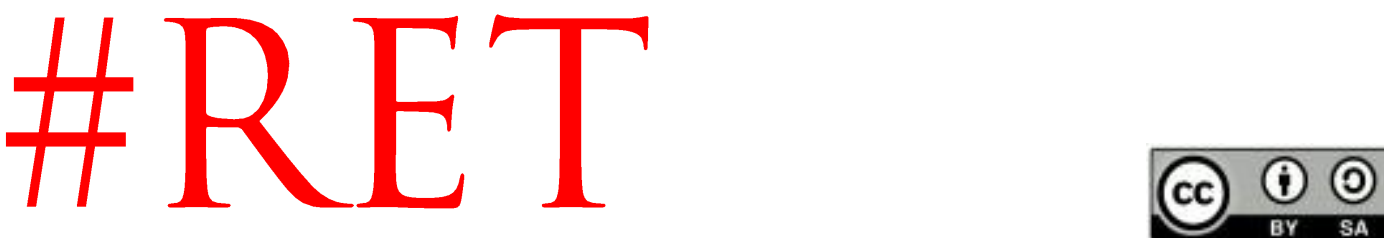

Revista Española de la Transparencia

Núm. 12. Primer Semestre. Enero-Junio de 2021, pp. 25-46.

ISSN 2444-2607. Www.revistatransparencia.com

DOI: https://doi.org/10.51915/ret.134

TRIBUNA: ENFOQUES Y DOCTRINA

\title{
El acceso a la información relativa a los procedimientos administrativos
}

\author{
Severiano Fernández Ramos ${ }^{1}$ \\ Catedrático de Derecho Administrativo \\ Universidad de Cádiz \\ España \\ ORCID: $0000-0002-9784-4503$ \\ RECIBIDO: 8 de marzo de 2021 \\ ACEPTADO: 8 de marzo de 2021
}

RESUMEN: Durante la vigencia de la Ley 30/1992 el acceso a la información procedimental estaba regido por una regla muy simple: en los procedimientos en curso el acceso se reservaba a los interesados en los mismos, de modo que los terceros únicamente podian acceder a los procedimientos terminados. En cambio, a partir de la Ley 19/2013, de 9 de diciembre, la accesibilidad a la información procedimental, tanto por parte de los interesados como de la ciudadanía en general, responde a parámetros diversos, no exentos de controversia entre los propios órganos de garantía del derecho, y sobre los cuales trata este trabajo.

PALABRAS CLAVE: información pública, procedimiento administrativo.

\footnotetext{
${ }^{1}$ Catedrático de Derecho Administrativo de la Universidad de Cádiz. Cuenta con cuatro sexenios de investigación y ha desarrollado una intensa actividad investigadora en materia de transparencia y Buen Gobierno como antítesis a la corrupción. Es coautor (junto a José $M^{a}$ Pérez Monguió) de las siguientes monografías en la prestigiosa editorial Thomson Reuters-Aranzadi: La imparcialidad en el procedimiento administrativo (2012), La Ley de Transparencia, Acceso a la Información Pública y Buen Gobierno (2014), El Estatuto de los Altos Cargos (2016), El derecho de acceso a la información pública en España (2017), y Voz Pópuli. Consultas populares y procesos participativos (2019)
} 
CONTENIDOS: 1. El acceso a la información procedimental en la Ley 30/1992. 2. Los nuevos parámetros de la LTAIBG. 3. El acceso a la información relativa a un procedimiento terminado. 3.1. El acceso por parte de terceros. 3.2. El acceso por parte de los propios interesados. 4. El acceso a la información relativa a un procedimiento en curso. 4.1. El acceso por parte de los interesados conforme a la legislación de procedimiento administrativo. 4.2. El acceso por parte de terceros conforme a la LTAIBG. 4.3. ¿Acceso por parte de interesados conforme a la LTAIBG?

\section{Access to information related to administrative procedures}

ABSTRACT: During the validity of Law 30/1992, access to procedural information was governed by a very simple rule: in ongoing procedures, access was reserved to those interested in them, so that third parties could only access the procedures. finished. On the other hand, as of Law 19/2013, of December 9, the accessibility to procedural information, both by the interested parties and the general public, responds to various parameters, not exempt from controversy between the bodies themselves. guarantee of the right, and about which this work deals.

KEYWORDS: public information, administrative procedure. 


\section{El acceso a la información procedimental en la Ley 30/1992}

Como es conocido, el entonces llamado derecho de acceso a los archivos y registros administrativos previsto (más que regulado) en la Ley 30/1992, de 26 de noviembre, de Régimen Jurídico de las Administraciones Públicas y del Procedimiento Administrativo Común, estaba limitado expresamente a los procedimientos terminados (art. 37.1), limitación que fue recogida en múltiples normas estatales y autonómicas². Al mismo tiempo, la Ley 30/1992 [art. 35.a)] reconocía el tradicional derecho de los interesados a conocer, en cualquier momento, el estado de tramitación de los procedimientos y a obtener copias de los documentos contenidos en ellos.

En este sentido, recogiendo un criterio procedente de normas reglamentarias de desarrollo de la antigua Ley de Procedimiento Administrativo de 1958³, el Real Decreto 208/1996, de 9 de febrero, por el que se regulan los servicios de información administrativa y atención al ciudadano (aplicable a la Administración General del Estado), dispuso -art. 3- que la información particular (a diferencia de la llamada «información general) «Es la concerniente al estado o contenido de los procedimientos en tramitación, y a la identificación de las autoridades y personal al servicio de la Administración General del Estado y de las entidades de derecho público vinculadas o dependientes de la misma bajo cuya responsabilidad se tramiten aquellos procedimientos. Esta información sólo podrá ser facilitada a las personas que tengan la condición de interesados en cada procedimiento o a sus representantes legales de acuerdo con lo dispuesto en los artículos 31 y 32 de la Ley 30/1992». Y esta distinción entre información general y particular fue adoptada también por diversas normas autonómicas, algunas relativamente recientes ${ }^{4}$.

\footnotetext{
${ }^{2}$ Así, el Decreto-Legislativo 2/2001 del T.R. Ley de Administración de Aragón -art. 52.3- dispuso que el derecho de acceso a los archivos y registros tendrá efectividad únicamente en relación con los procedimientos administrativos que se encuentren terminados en la fecha en la que se solicita el ejercicio de este derecho; añadiendo que se entenderá por procedimiento administrativo terminado aquél en el que se haya producido una resolución definitiva en vía administrativa -art. 52.3-. En el mismo sentido, la Ley 9/2007, de 22 de octubre, de Administración de la Junta de Andalucía, estableció que la ciudadanía tiene derecho a acceder a los archivos y registros administrativos «en los términos previstos en la normativa básica vigente. El derecho de acceso a los archivos y registros solo podrá ejercerse en relación con procedimientos terminados en la fecha de la solicitud»-art. 86-. Por su parte, la Ley 26/2010, de 3 de agosto, de régimen juridico y de procedimiento de las administraciones públicas de Cataluña, establece que los ciudadanos tienen derecho a acceder, por cualquier medio, a los registros y a los documentos que formen parte de un expediente y obren en los archivos de las administraciones públicas catalanas, siempre que tales expedientes correspondan a procedimientos terminados en la fecha de la solicitud -art. 26-.

${ }^{3}$ La distinción entre información general y particular procede de la Orden de la Presidencia de 22 de octubre de 1958.

${ }^{4}$ Decreto 21/2002, de 24 enero, por el que se regula la atención al ciudadano en la Comunidad de Madrid (art. 9); Decreto 57/2006, de 27 de octubre, por el que se regula la atención al ciudadano en la Comunidad Autónoma de La Rioja (art. 7); Decreto 44/2007, de 27 de febrero, por el que se regula el servicio de información y atención ciudadana en la Administración Pública de la Comunidad Autónoma de Canarias; Decreto n. ${ }^{\circ}$ 236/2010, de 3 de septiembre, de Atención al Ciudadano en la
} 
De este modo, en la economía de la Ley 30/1992, existía una clara y neta separación entre, de un lado, procedimientos en curso, cuyo acceso se reservaba a los interesados en el mismo y, de otro lado, procedimientos terminados, cuyo acceso podía ser solicitado por terceros. Una distinción que tenía la ventaja de su sencillez, y que en cierto modo se interiorizó por las Administraciones públicas, si bien dio también lugar a interpretaciones cuestionables por su desmesurada amplitud $^{5}$. Lo cierto es que restringir el acceso a la información sobre procedimiento terminados también a los interesados habría supuesto, sencillamente, reducir el derecho de acceso del artículo 37 de la Ley 30/1992 a la más absoluta inanidad.

Ahora bien, esta exigencia de terminación del procedimiento fue criticada por la doctrina ${ }^{6}$, y constituyó uno de los motivos por los cuales la ordenación del derecho de acceso a los archivos y registros de la Ley 30/1992 no pudo en su día servir de transposición de la previa Directiva 90/313/CEE, de 7 de junio, de libertad de acceso a la información ambiental, obligando al Estado español a aprobar una ley específica para incorporar dicha directiva al ordenamiento español 7 . Y, de hecho, en relación con la normativa de acceso a la información ambiental, la jurisprudencia, tanto comunitaria como nacional, dejó bien claro que no rige la

Administración Pública de la Región de Murcia (art. 11); Decreto Foral 54/2010, de 6 de septiembre, por el que se regulan los servicios de información y atención ciudadana en la Administración de la Comunidad Foral de Navarra (art. 7); Ley 1/2015, de 1 de abril, de garantía de la calidad de los servicios públicos y de la buena administración de Galicia (art. 12 relativo a la información particular).

${ }^{5}$ Por ej, la STSJ de Castilla y León (Burgos) 131/2004, de 1 de abril (Número de Recurso: 390/2002). En este caso una empresa propietaria de varias fincas que eran objeto de un expediente de expropiación para la ejecución de ciertas infraestructuras solicitó al Ayuntamiento de Burgos determinada documentación acerca de dichas obras que ya se estaban ya ejecutando. Por su parte, el Tribunal llegó a la conclusión que "la parte actora no podía tener acceso a los documentos y certificados solicitados y que le fueron denegados, toda vez que tales documentos forman parte de un procedimiento administrativo, relativo a la ejecución de las obras de dicha variante ferroviaria, que en la actualidad no se encuentra terminado, como lo corrobora el hecho de que tales obras continúen realizándose. Por tanto, la denegación de tales documentos con apoyo en dicho precepto es plenamente ajustada a derecho".

6 Vid. S. FERNÁNDEZ RAMOS (1997: 438-441), donde se indica que esta restricción no podía encuadrarse en modo alguno en las consecuencias dogmáticas de la noción de documento administrativo como objeto entonces del derecho de acceso, pues el requisito de la terminación del documento nada tiene que ver con la terminación del procedimiento en el curso del cual se ha producido. De este modo, se argumentó que la exigencia del legislador debía considerarse un límite externo al derecho de acceso, y al operar de un modo rígido, sin valorar el hecho de que no siempre el acceso por parte de terceros a un documento perjudica el buen fin de la instrucción, se defendió que esta condición legal constituye una limitación susceptible de lesionar el principio de congruencia o proporcionalidad en la delimitación de los límites de los derechos constitucionales.

${ }^{7}$ La derogada Ley 38/1995, de 12 de diciembre, del derecho de acceso a la información en materia de medio ambiente, reconoció expresamente esta limitación de la Ley 30/1992 en su exposición de motivos: «En la Ley 30/1992 el derecho de acceso y las causas por las que se puede denegar su ejercicio quedan limitados a los registros y a los documentos que, formando parte de un expediente, obren en los archivos administrativos, siempre que tales expedientes correspondan a procedimientos terminados en la fecha de la solicitud, exigencia ésta ausente en la Directiva».

Revista Española de la Transparencia. RET. ISSN 2444-2607

Núm. 12. Primer Semestre. Enero-Junio de 2021, pp. 25-46

DOI: https://doi.org/10.51915/ret.134 
exigencia de que el documento al que se pretenda acceder corresponda a un procedimiento terminado ${ }^{8}$.

\section{Los nuevos parámetros de la LTAIBG}

En este estado de cosas, la disposición adicional primera de la Ley 19/2013, de 9 de diciembre, de transparencia, acceso a la información pública y buen gobierno (en adelante, LTAIBG, que lleva por título Regulaciones especiales del derecho de acceso a la información pública, declara en su apartado 1 lo siguiente: «La normativa reguladora del correspondiente procedimiento administrativo será la aplicable al acceso por parte de quienes tengan la condición de interesados en un procedimiento administrativo en curso a los documentos que se integren en el mismo»?.

Como puede verse, la aplicación de este régimen especial requiere de la conjunción de dos condiciones ${ }^{10}$ :

- Una condición subjetiva: sólo pueden hacer uso de este régimen las personas que tengan la condición de interesados en un concreto procedimiento administrativo. Para determinar la condición de interesado en un procedimiento habrá que estar, evidentemente, a lo dispuesto en la Ley 39/2015, de 1 de octubre, de Procedimiento Administrativo Común de las Administraciones Públicas -art. 4.1- (en adelante, LPAC).

- Una condición temporal: el procedimiento ha de estar en curso. Dada la relevancia de esta circunstancia, debemos realizar algunas precisiones sobre qué ha de entenderse por procedimiento en curso o, por el contrario, concluido.

\footnotetext{
${ }^{8}$ STS 17 de febrero de 2004, recurso 3457/2000, en relación con una solicitud de acceso a unas actas de inspección, el Alto Tribunal declaró que "tratar de denegar la información con el soporte jurídico de que las actas de inspección son, simplemente un «documento inconcluso», no resulta aceptable. «Tales actas no son -aunque pudieran serlo-- un elemento de un procedimiento sancionador; como tal documento público el acta está dotada de sustantividad y esencia propia, así como de una finalidad concreta cual es la de constatación de hechos, que podrán -o no-ser utilizados, con posterioridad, en otro tipo de procedimiento. Son el resultado de las actuaciones de comprobación e investigación, pudiendo incluso contener una propuesta de actuación. Pero, desde tal perspectiva, no son documentos inconclusos o inacabados, ni la constatación de hechos que contiene es simplemente indicativa o indiciaria, pues la misma está dotada de un especial valor probatorio al margen de su posterior, o no, utilización». Y, en esta línea, la posterior STS de 3 de octubre de 2006 (RJCA 2006\10071), declaró que interpretadas correctamente la Directiva 1990/313 y la Ley 38/1995, e interpretado correctamente el artículo 3.3 de una y otra, debió facilitarse información de los documentos obrantes en los expedientes que, (1) siendo separables, (2) estuvieran - ellos, los documentos- conclusos.

9 En este sentido, la Ley 19/2014, de 29 de diciembre, de transparencia, acceso a la información pública y buen gobierno de Cataluña, dispone (disposición adicional primera): «El acceso de los interesados a los documentos de los procedimientos administrativos en trámite se rige por lo que determina la legislación sobre régimen jurídico y procedimiento administrativo».
}

10 Así, Consejo de Transparencia y Buen Gobierno (en adelante, CTBG), R/0399/2016, 25 de noviembre de 2016 . 
A este respecto, la LPAC -art. 84.1- establece que pondrán fin al procedimiento la resolución, el desistimiento, la renuncia al derecho en que se funde la solicitud ${ }^{11}$ y la declaración de caducidad. Pero también produce la terminación del procedimiento la imposibilidad material de continuarlo por causas sobrevenidas art. 84.2-, así como la terminación convencional, cuando ésta tenga la consideración de finalizadora del procedimiento -art. 86.1-. Asimismo, debe entenderse que, en los procedimientos en susceptibles de producir efectos desfavorables o de gravamen, la caducidad del procedimiento no requiere ser declarada [«se producirá la caducidad»-art. 25.1.b)-]. Pero, sobre todo, debe entenderse que, en los casos de silencio administrativo, el procedimiento también ha concluido a estos efectos, pues la resolución expresa que pueda dictar la Administrativo es tratada por la Ley como una resolución extemporánea -art. 24.3-. De otro lado, hay que descartar que para dar por terminado un procedimiento sea preciso que la resolución (expresa o presunta) sea firme, ni mucho menos ejecutada en todos sus términos, pues tales exigencias adicionales carecen de apoyo legal ${ }^{12}$.

Asimismo, en el caso de procedimientos selectivos o de concurrencia competitiva, entiendo que, desde el momento en que un interesado es expulsado del procedimiento ( $p$. ej., por no superar una de las fases, como pueda ser la de oposición en un concurso-oposición), o bien para esa persona el procedimiento ha terminado, o bien ha perdido la condición de interesado en el mismo (de hecho, no puede seguir participando en el procedimiento), por lo que, en cualquier caso, no será ya de aplicación el apartado 1 de la D. A. $1^{\text {a }}$ LTAIBG $^{13}$.

\footnotetext{
${ }^{11}$ En propiedad, el desistimiento y la renuncia no tienen por efecto, en todo caso, la terminación del procedimiento (véase art. 94.3 LPAC).

12 Véase sobre estas cuestiones en la Ley 30/1992, S. FERNÁNDEZ RAMOS (1997: 444-446). Sin embargo, el CTBG parece exigir esta firmeza del acto, al añadir los plazos para recurrir en vía administrativa y contenciosa el acto (p. ej., R/0178/2020).

${ }^{13}$ Asi puede inferirse del asunto sobre el que recayó la STSJ Castilla y León (Valladolid) 1253/2019, de 24 de octubre.
} 


\section{El acceso a la información relativa a un procedimiento terminado}

\subsection{El acceso por parte de terceros}

Con independencia de lo que más adelante se dirá sobre los procedimientos en curso, parece claro que, una vez terminado el procedimiento, el derecho de acceso regulado en la LTAIBG puede ser ejercido directamente por terceros, como -por lo demás- ya sucedia en el régimen de la derogada Ley 30/1992. Es decir, habrá que convenir que, como mínimo, la LTAIBG mantiene el limitadísimo estándar de accesibilidad que ya contemplaba la denostada (con razón) Ley 30/1992. De hecho, si no se puede acceder ni siquiera a los procedimientos ya terminados, ¿a qué se puede acceder? Y, en todo caso, así se ha pronunciado el CTBG ${ }^{14}$.

Ahora bien, esta afirmación elemental plantea ya la falta de conformidad con la ley básica de determinadas normas autonómicas, alguna incluso posterior a la LTAIBG, que han extendido la noción de información «particular» de la concerniente al estado o contenido de los procedimientos administrativos «en tramitación» (tal como aún establece el Real Decreto 208/1996, de 9 de febrero), a los procedimientos $\ll$ finalizados» ${ }^{15}$. En nuestra opinión, esta noción de información «particular», en el sentido de reservada a los interesados, es frontalmente contradictoria con el concepto de información pública de la LTAIBG y, por tanto, incurre en una manifiesta inconstitucionalidad indirecta.

\subsection{El acceso por parte de los propios interesados}

Dado que la aplicación de la normativa procedimental requiere, como se ha indicado, de la doble exigencia de que el solicitante tenga la condición de interesado en un procedimiento administrativo y que éste se encuentre en curso, parece lógico entender que, una vez terminado el procedimiento, el acceso a la documentación del mismo a través de la LTAIBG es posible tanto por parte de los terceros como por parte de los que tuvieron, mientras el procedimiento estuvo en curso, la condición de interesados en el mismo, pues incluso en este segundo caso

\footnotetext{
${ }^{14}$ El CTBG reconoce que la literalidad de la disposición adicional primera, habla de procedimientos administrativos en curso. R/0095/2015; R/0385/2016, 15 de noviembre de 2016. Así, entiende que una vez finalizado el procedimiento, no es de aplicación la disposición adicional $1^{\mathrm{a}}$ y el interesado puede hacer uso de la LTAIBG. CTBG, R/O413/2016, 14 de diciembre de 2016, Resolución 25 de septiembre de 2017 (R/0309/2017). En cambio, no parece entenderlo así el Consejo de Transparencia y Protección de Datos de Andalucía (CTPDA, RES/036/2016, de 1 de junio 2016), el cual ante una petición relativa a la identificación del "conjunto de funcionarios que de forma parcial o total hayan ejercido las potestades públicas durante la tramitación de mi expediente", considera que dicha petición constituye un derecho encuadrable en el artículo 35.b) de la Ley 30/1992, por lo que excede del ámbito objetivo de la Ley de Transparencia. Cuestión distinta es si la información solicitada estaba o no disponible o requería de un proceso de elaboración.

15 Decreto 44/2007, de 27 de febrero, por el que se regula el servicio de información y atención ciudadana en la Administración Pública de la Comunidad Autónoma de Canarias (art. 12.1); Ley 1/2015. de 1 de abril, de garantía de la calidad de los servicios públicos y de la buena administración (art. 12.1). De hecho, estas normas no se ajustaban ya ni siquiera a los parámetros de la Ley 30/1992.
} 
no cabe aplicar la regla del apartado 1 de la DA $1^{\text {a }}$. De hecho, si es indubitado como se ha señalado- el acceso por parte de terceros, con mayor razón habría que entender el ejercicio del derecho por aquellos que ostentaron un interés cualificado ${ }^{16}$.

Sin embargo, debe observarse que se repiten resoluciones jurisdiccionales que parecen excluir que, una vez terminado el procedimiento, quienes fueran interesados en el mismo puedan plantear una solicitud de acceso a la información pública en aplicación de la LTAIBG, alegando además que no es función de esta Ley comprobar la regularidad de la actuación en la que los solicitantes fueron parte interesada, por esgrimir éstos un interés personal ajeno a la LTAIBG ${ }^{17}$.

Peor aún, esta postura ha ido cobrando cuerpo en la doctrina del propio CTBG, el cual ha añadido lo siguiente (R/0178/2020): «(...), este Consejo de Transparencia y Buen Gobierno es consciente de que, como ocurre también en este supuesto, es dificil sustraer del amparo de la LTAIBG -incluyendo el mecanismo de impugnación ante el Consejo de Transparencia y Buen Gobierno previsto en la norma- a aquellos supuestos en los que se solicita información pública- entendida en sentido amplio como todo contenido o documento que obre en poder de organismos públicos según el art. 13 de la LTAIBG -cuando el procedimiento administrativo al que se refiere la solicitud ya hubiera concluido- y ello, entendiendo la disposición adicional primera de la LTAIBG a sensu contrario. Y ello por cuanto la disposición cuya aplicación alegaba la Administración en este caso se limita a los supuestos en los que la solicitud cumpla con dos condicionantes: sea presentada por el interesado y se refiera a un procedimiento en curso. Ello llevaria a plantearse el hecho de que, cuando la solicitud no cumpla con alguna de ellas, no sea posible alegar la reiterada disposición adicional primera apartado 1. Es esta circunstancia la que precisamente ocurre en el caso que nos ocupa.

\footnotetext{
${ }^{16}$ En Portugal, donde existe una remisión similar a la legislación de procedimiento administrativo en el caso de solicitudes de acceso al expediente por parte de interesados en el mismo, si bien la Comisión de Acceso a los Documentos Administrativos se declaró en un inicio incompetente en estos casos de informaciones procedimentales cuando aún no ha concluido el procedimiento, esta orientación fue objeto de revisión (voto particular del sr. Castro Martins al "parecer" CADA, 47/2002, Alta Autoridade para a Comunicação Social).

17 Juzgado Central C-A no 4, sentencia 49/2020, de 18 de mayo, procedimiento ordinario 53/2019. Se trataba de un procedimiento de adjudicación de contratos públicos. La sentencia añade: «El interés del peticionario era poner de manifiesto la incorrecta ejecución del contrato, pues se estaba ejecutando por terceras. empresas y profesionales con licencias VTC y no por la propia empresa adjudicataria, lo que no se compadece con la finalidad de control de la actuación pública a que responde la Ley de Trasparencia, que era conocer los términos del proceso de contratación, pues se está poniendo en cuestión la conducta de la adjudicataria en una fase en que no estaba comprometida la actuación de la SME RENFE. Ello es manifestación además de un interés particular, en defensa del cual el peticionario ha podido ejercitar las acciones procedentes en restablecimiento de su derecho». Pero el mismo criterio se repite en la sentencia del Juzgado Central C-A $n^{\circ} 2$ $33 / 2020$, de 12 de mayo, procedimiento ordinario 29/2019-C, aplicada a un procedimiento de selección de funcionario, cuando éste ya había finalizado: «En semejante tesitura, el legítimo el interés del aspirante a conocer los exámenes de otros y las actas de las Comisiones Delegadas en que se contienen las calificaciones desglosadas de los mismos, no se compadece con la finalidad de control de la actuación pública a que responde la Ley de Trasparencia, y es manifestación antes bien del interés particular en verificar que su examen ha sido correctamente valorado».
}

Revista Española de la Transparencia. RET. ISSN 2444-2607 
Sin embargo, y tal y como pretendemos señalar, a nuestro juicio, la aplicación de la Ley de Transparencia para acceder a un concreto expediente administrativo cuando es un derecho que le es reconocido al solicitante en su condición de interesado, podría entenderse como un uso no plenamente conforme con la finalidad de la LTAIBG expresadas tanto en su Preámbulo (...) como en la definición de su objeto (ampliar y reforzar la transparencia de la actividad pública, regular y garantizar el derecho de acceso a la información relativa a aquella actividad y establecer las obligaciones de buen gobierno que deben cumplir los responsables públicos asi como las consecuencias derivadas de su incumplimiento).

En definitiva y aunque, como señalamos, la redacción de la LTAIGB no lo impide, no podemos sino señalar que, a nuestro juicio, el acceso a la documentación obrante en un expediente administrativo por el interesado en el mismo deberia realizarse siempre y en todo caso al amparo de la Ley 39/2015».

A mi juicio, estas afirmaciones, además de gratuitas, son profundamente erróneas. Partiendo de la premisa indubitada según la cual los documentos que integran los procedimientos administrativos terminados son información pública a efectos de la LTAIBG, cuando una persona que «tuvo» la condición de interesada en un procedimiento ya concluido solicita acceder a la información relativa al mismo pueden darse dos supuestos. La primera posibilidad es que el solicitante no haga valer su interés cualificado en el acceso a la información, algo a lo que no está obligado -art. 17.3-. En este caso, ni la Administración ni menos aún los órganos de control (administrativos o jurisdiccionales) están legitimados para tomar en consideración la circunstancia según la cual el solicitante «tuvo» la condición de interesado en un procedimiento, condición que -subrayamos- es pretérita, pues se perdió al terminar el procedimiento. La segunda posibilidad es que el solicitante sí haga valer su interés cualificado en el acceso a la información derivado de su anterior condición de interesado en el procedimiento. Pues bien, en este caso la LTAIBG es muy clara: la Administración (y, en su caso, los órganos de revisión) está obligada a valorar (positivamente, se entiende) este interés privado -arts. 14.2 y $15 \cdot 3^{-18}$.

$Y$, en fin, cuando se dice que no es finalidad de la LTAIBG atender peticiones de acceso a información pública por parte de interesados, parece olvidarse que contribuir al respeto a la legalidad administrativa es la primera finalidad de la transparencia pública. Dicho de otro modo, cuando un licitador se considera indebidamente preterido en la adjudicación de un contrato público, o un candidato injustamente evaluado en un procedimiento selectivo, y solicitan acceder al expediente administrativo, ciertamente no actúan prima facie de forma desinteresada en pro de la transparencia, pero sí es evidente que con su actuación contribuyen al respeto de la legalidad pública, amén de la defensa de los intereses

${ }^{18}$ Así, p. ej., la GAIP, en su Resolución 45/2018, 
públicos tuteladas por esta (como la igualdad de trato, la tutela de la competencia, o del derecho de acceso a los cargos públicos.... ${ }^{19}$.

\section{El acceso a la información relativa a un procedimiento en curso}

\subsection{El acceso por parte de los interesados conforme a la legislación de procedimiento administrativo}

Como se indicó más arriba, la legislación sobre procedimiento administrativo viene reconociendo el derecho de los que tengan la condición de interesados a conocer, en cualquier momento, el estado de tramitación de los procedimientos y a obtener copias de los documentos contenidos en ellos. $Y$ debe advertirse que se trata de un derecho procedimental históricamente muy anterior al derecho de acceso a la información pública entendido como derecho ciudadano, remontándose a las normas procedimentales del siglo XIX, y que se plasmó de forma definitiva en la Ley de Procedimiento Administrativo de $1958^{20}$. Un derecho procedimental que en algunas formulaciones legales recientes ha venido a integrarse en el moderno derecho a una buena administración ${ }^{21}$.

Este derecho de acceso al expediente administrativo por parte de los interesados en el correspondiente procedimiento se trata de una garantía procedimental, que forma parte del derecho a la defensa, pues es instrumental respecto al derecho de los interesados a formular alegaciones y a aportar documentos tanto en cualquier fase del procedimiento anterior al trámite de audiencia -art. 76.1 LPAC-, como en el mismo trámite de audiencia -art. 82.2 LPAC-, e incluso en caso de actuaciones complementarias -art. 87 LPAC-. Asimismo, de modo adjetivo, este derecho constituye el medio a través del cual el interesado puede tomar conocimiento preciso de las actuaciones que la Administración está llevando a cabo en

\footnotetext{
${ }^{19}$ Cuando el sr. López Ostra llegó hasta el Tribunal de Estrasburgo en defensa de su derecho a la intimidad en un caso de contaminación acústica es evidente que, primariamente, luchaba por su interés personal, pero ¿acaso su victoria en la sentencia de 9 de diciembre de 1994 no se sintió como una victoria de todos?

20 La formulación primigenia de este derecho procede de la Revolución de Septiembre de 1868 , cuando se dictó el Decreto de 30 de noviembre de 1870, por el que se aprueba el Reglamento del Ministerio de la Gobernación -arts. 65 y 67-, el cual dispuso que, en los expedientes incoados a instancia de parte, los que sean parte del mismo tendrán derecho a enterarse por medio del Registro general o el de la sección y en las horas de audiencia, del estado y curso del expediente. La figura sería generalizada por el Real Decreto de 14 de septiembre de 1872, para todos los Ministerios: «Igualmente (todas las dependencias) contestarán en el término de diez dias a los que pregunten por el estado de cualquiera reclamación que tengan pendiente en las mencionadas dependencias. Estas preguntas se harán por escrito...» (art. 8). Como puede verse, este derecho no comportaba el acceso directo por el interesado al mismo, sino que era un derecho a ser informado por los agentes al servicio de la Administración. Posteriormente, la figura pasaria por distintas formulaciones hasta su plasmación definitiva en la Ley de Procedimiento Administrativo de 1958, adoptada con leves variaciones por la Ley 30/1992. Véanse S. FERNANDEZ RAMOS (1997: 255 y ss.); O. MIR PUIGPELAT (2019: 21 y ss.).

${ }^{21}$ La reforma del Estatuto de Autonomía de Canarias, llevada a cabo por la Ley Orgánica 1/2018, de 5 de noviembre, dispone que el derecho a una buena administración comprende, entre otros, el derecho a la información integral sobre los servicios y prestaciones, «y el estado de la tramitación de los asuntos que le conciernan»-art. 32.a)-.
} 
cumplimiento de su obligación de impulsar el expediente, y poder advertir así a la Administración sobre eventuales demoras o dilaciones indebidas en la tramitación del procedimiento y, en general, alegar defectos en la tramitación -arts. 53.1.e) y 76.2 LPAC-.

Siguiendo parcialmente a la anterior Ley 30/1992, la LPAC -art. 53.1.a)- reconoce el derecho de los interesados en un procedimiento administrativo «A conocer, en cualquier momento, el estado de la tramitación de los procedimientos en los que tengan la condición de interesados; el sentido del silencio administrativo que corresponda, en caso de que la Administración no dicte ni notifique resolución expresa en plazo; el órgano competente para su instrucción, en su caso, y resolución; y los actos de trámite dictados. Asimismo, también tendrán derecho a acceder y a obtener copia de los documentos contenidos en los citados procedimientos». Pero, debido a la parquedad de la Ley, no es claro el régimen de este derecho instrumental.

Así, en cuanto al objeto del derecho, una interpretación literal del precepto derecho a conocer "el estado de tramitación"- podría llevar a pensar que se trata de una mera pretensión de conocimiento del estado en el que se encuentra un procedimiento -de sus fases, de las actuaciones que ha practicado la Administración-. Y esta interpretación estaría reforzada debido a los añadidos introducidos por la LPAC 2015 («el sentido del silencio administrativo que corresponda, en caso de que la Administración no dicte ni notifique resolución expresa en plazo; el órgano competente para su instrucción, en su caso, y resolución»), consistentes en una mera prestación informativa. De hecho, en la práctica, a menudo el contenido de este derecho es muy limitado.

Por el contrario, si se interpreta sistemáticamente este derecho con el derecho a obtener copia de los documentos contenidos en los procedimientos, puede defenderse que el primero alcanza -no obstante su deficiente redacción- al contenido de actuaciones concretas, pues si existe un derecho subjetivo a obtener copias de todos los documentos contenidos en el expediente -y no ya, como disponía de la Ley de 1958, de aspectos concretos-, parece evidente que este derecho implica que el derecho de información alcanza también a todos los documentos del procedimiento. Y, en este sentido, el RD 208/1996 -art. 3.1- refiere la información particular "al estado o contenido de los procedimientos en tramitación" 22. Así, debe recordarse que el inciso final del artículo 53.1.a) (que no se

\footnotetext{
22 De forma más clara, la Ley $26 / 2010$, de 3 de agosto, de régimen jurídico y de procedimiento de las administraciones públicas de Cataluña, bajo el rótulo derecho de acceso a los expedientes administrativos, si declara «derecho a acceder al expediente»-art. 26-. En cambio, la derogada Ley 11/2007, de 22 de junio, de acceso electrónico de los ciudadanos a los servicios públicos, parecía consagrar no un acceso, más o menos completo o parcial, al expediente en sí, sino a una «información sobre el estado del procedimiento». En efecto, en el caso de procedimientos administrativos gestionados total o parcialmente de modo electrónico la Ley 11/2007 establece un alcance diverso del acceso al expediente por esta vía: a) si el procedimiento se gestiona en su totalidad electrónicamente, el órgano que tramita el procedimiento pondrá a disposición del interesado un servicio electrónico de acceso restringido donde éste pueda consultar, previa identificación, la información sobre el estado de tramitación del procedimiento, que comprenderá la relación de los actos
} 
encontraba en la Ley 30/1992) se refiere al derecho a conocer «los actos de trámite dictados».

De este modo, el contenido de este derecho de los interesados se plasma en la documentación contenida en el expediente administrativo, esto es, el conjunto ordenado de documentos y actuaciones que sirven de antecedente y fundamento a la resolución administrativa, así como las diligencias encaminadas a ejecutarla art. 70.1 LPAC-. Así, se aprecian relevantes diferencias con el derecho de acceso a la información pública, pues el derecho de los interesados se circunscribe a la información documentada y contenida en el expediente. Y ello sin perjuicio de la obligación positiva que pesa sobre la Administración de integrar en el expediente todos los documentos relevantes ${ }^{23}$.

Pero tampoco están claros los límites de este derecho. Como ya hiciera antes la Ley 30/1992, la LPAC -art. 82.1, a propósito del trámite de audiencia- se remite a las limitaciones previstas en la propia LTAIBG. Sin embargo, parece lógico que condición de interesados comporta una posición cualificada, y que es funcional a su derecho de defensa en relación con al procedimiento del que son parte, de tal modo que el alcance del derecho ejercido por los interesados deberá ser, lógicamente, superior al ordinario del conjunto de los ciudadanos ${ }^{24}$.

Igualmente, tampoco es claro el modo de ejercicio del derecho, si bien el acceso no deberia ser a documentos aislados que deba identificar previamente el

de trámite realizados, con indicación sobre su contenido, asi como la fecha en la que fueron dictados; en el resto de los procedimientos se habilitarán igualmente servicios electrónicos de información del estado de la tramitación que comprendan, al menos, la fase en la que se encuentra el procedimiento y el órgano o unidad responsable -art. 37-..

${ }^{23}$ Auto del Tribunal Supremo de 13 de junio de 2018, recurso 690/2017: "El expediente administrativo, tal y como el propio art. 70.1 dispone, debe estar conformado por los documentos y actuaciones que «sirven de antecedente y fundamento a la resolución administrativa». La previsión contenida en el apartado 4 de dicho precepto, que permite excluir del expediente la «información que tenga carácter auxiliar o de apoyo», debe recibir una interpretación restrictiva, evitando que datos y elementos relevantes que sirvieron para conformar la decisión administrativa queden fuera del expediente remitido al órgano judicial, impidiendo a los afectados conocer datos o actuaciones que limiten su derecho de defensa y, por tanto, puedan generar indefensión. Sin perjuicio de que la exclusión de determinados elementos meramente auxiliares o de apoyo pueda ser posible al considerar que se trata de datos que resultan irrelevantes y no generan ningún tipo de indefensión. En todo caso, la conformación del expediente administrativo que se remita estará sometida a la solicitud de ampliación por los afectados y al control último del órgano judicial, pues como ya dijimos en la STS de 8 de mayo de 2015 (rec. 422/2014) «es el juez quien tiene la última y definitiva palabra tanto sobre el contenido e integración del expediente como sobre su ordenación y confección»".

\footnotetext{
${ }^{24}$ Así, E. GUICHOT (2017: 575) apunta que los derechos de contradicción y defensa deberian conllevar una inaplicación o una aplicación más reducida de los valores protegidos por algunos de los limites contemplados en el artículo 14 LTAIBG, como los relativos a la prevención, investigación y sanción de los ilícitos penales, administrativos o disciplinarios, las funciones administrativas de vigilancia, inspección y control, la garantía de la confidencialidad o el secreto requerido en procesos de toma de decisión, lo cual no deja de ser contradictorio con su postura absolutamente contraria a tomar en consideración la posición del solicitante. En esta línea y analizando el alcance de los principales limites y descartando la aplicabilidad de las causas de inadmisión (salvo evidentemente el ejercicio abusivo del derecho, al tratarse de un principio general del Derecho), O. MIR PUIGPELAT (2019: 99 y ss.).
}

Revista Española de la Transparencia. RET. ISSN 2444-2607

Núm. 12. Primer Semestre. Enero-Junio de 2021, pp. 25-46

DOI: https://doi.org/10.51915/ret.134 
interesado, sino que, una vez acreditada su condición de interesado (esto es, la identidad, sin necesidad de firma -art. 11.2 LPAC, a sensu contrario), éste ha de poder tener a su disposición el expediente completo (salvo aplicación de alguna excepción al derecho de acceso, en cuyo caso deberá hacerse constar al interesado esta circunstancia), todo ello a través del Punto de Acceso General electrónico de la Administración, tal como prevé expresamente la LPAC -art. 53.1.a)-, lo cual posibilitaría que el acceso al expediente se efectuase mediante sistemas automatizados, sin intervención de personas físicas ${ }^{25}$.

Lo que sí establece con meridiana claridad la LPAC es que el derecho puede ejercerse «en cualquier momento» (mientras el procedimiento esté abierto). Así, la GAIP ha declarado que la Administración no puede determinar cuál es el momento en el cual debe el interesado ejercitar su derecho ${ }^{26}$. Asimismo, la nueva redacción de la LPAC ( «Asimismo, también tendrán derecho a acceder y a obtener copia de "los" documentos contenidos en los citados procedimientos) permite superar una interpretación restrictiva del alcance del derecho a obtener copias de los documentos que había impuesto el Tribunal Supremo a partir de una interpretación literal de la Ley $30 / 1992^{27}$.

De otro lado, en caso de denegación del acceso al expediente en curso por parte de los interesados, habrá de considerarse el acto de denegación como un acto de trámite del procedimiento principal, aplicándose la regla general de la LPAC -art. 112.1-, según la cual no cabe interponer un recurso autónomo, salvo que se

\footnotetext{
${ }^{25}$ El derogado Real Decreto 1398/1993, de 4 de agosto, por el que se aprobó el Reglamento del Procedimiento para el Ejercicio de la Potestad Sancionadora, bajo el epígrafe precisamente de "Transparencia del procedimiento" -art. 3-, establecía una regla de gran interés, según la cual «El procedimiento se desarrollará de acuerdo con el principio de acceso permanente. A estos efectos, en cualquier momento del procedimiento, los interesados tienen derecho a conocer su estado de tramitación y a acceder y obtener copias de los documentos contenidos en el mismo», principio que podría generalizarse a cualquier procedimiento. Sin embargo, la LPAC no sólo no generalizó este principio de acceso permanente, sino que, y a diferencia de otras muchas reglas del Real Decreto 1398/1993, no incorporó esta regla al procedimiento sancionador. Véanse las interesantes propuestas de O. MIR PUIGPELAT (2019: 113 y ss.), quien apunta a un ejercicio y satisfacción prevalentemente informal del derecho, salvo que la comunicación del documento objeto de petición pueda afectar a terceros, así como la crítica a este apartado segundo del artículo 53.1.a) LPAC, por no reconocer expresamente a los interesados el derecho al acceso telemático al expediente.

${ }^{26}$ Comisión de Garantía del Derecho de Acceso a la Información Pública de Cataluña (en adelante. GAIP), Resolución 247/2020, de 9 de abril: «Por lo tanto, limitar el ejercicio del derecho de acceso al proyecto solicitado a los momentos de información pública y de audiencia a las personas interesadas, como pretenden hacer el DTS y la empresa promotora afectada, supone una restricción del derecho de acceso a esta misma información garantizado para las personas interesadas por el artículo 53.1 LPAC, que tiene carácter básico».

27 El artículo 35.a) de la Ley 30/1992 reconocía el derecho a «obtener copias de documentos contenidos en ellos» (los procedimientos). Pero el Tribunal Supremo (STS 26 de enero de 2011) entendió que, en la medida en que el precepto hablaba de "copia de documentos" y no de copia de los documentos, la Ley no reconocía un derecho a atender peticiones genéricas de copias del expediente, sino que las peticiones debian individualizarse. En cambio, como señala O. MIR PUIGPELAT (2019: 119-120), la vigente LPAC ya no habla de "copia de documentos", sino de "copia de los documentos".
}

Revista Española de la Transparencia. RET. ISSN 2444-2607

Núm. 12. Primer Semestre. Enero-Junio de 2021, pp. 25-46

DOI: https://doi.org/10.51915/ret.134 
considere que la falta de acceso al expediente causa indefensión, lo cual no es descartable en determinados procedimientos, como los sancionadores.

Finalmente, debe observarse que la disposición adicional $1^{\text {a }}$ de la LTAIBG se refiere a la «normativa reguladora del correspondiente procedimiento administrativo», de tal modo que la remisión no es exclusivamente a la Ley de Procedimiento Administrativo Común, sino también a las normas especiales relativas a procedimientos específicos (como sería el caso de la legislación sobre contratación pública).

\subsection{El acceso por parte de terceros conforme a la LTAIBG}

Hasta aqui hemos establecido que, una vez concluido el procedimiento, la información relativa al mismo es, inicialmente, accesible a todos. $\mathrm{Y}$, mientras el procedimiento esté en curso, los interesados en el mismo pueden ejercer el derecho de acceso a la información que les confiere la legislación de procedimiento. Pero, como hemos señalado antes, todo esto ya se reconocía con la Ley 30/1992. La cuestión es si, tas la LTAIBG, existen avances en esta materia.

Pues bien, la propia exposición de motivos de la LTAIBG reconoce expresamente que una de las deficiencias de la ordenación de la Ley 30/1992 fue limitar el derecho de acceso «a documentos contenidos en procedimientos administrativos ya terminados». Si a esta declaración expresa del legislador añadimos el hecho de que la LTAIBG no limita expresamente el derecho de acceso a la información pública a procedimientos terminados, parece obligado entender que esta limitación no rige ya con carácter general ${ }^{28}$. Asimismo, obsérvese que la disposición adicional primera se limita a reenviar el acceso a la información pública a la legislación de procedimiento para el caso de que confluyan dos circunstancias: procedimientos en curso e interesados, de modo que no es legítimo inferir de aquí una prohibición de acceso a terceros conforme al régimen general de la LTAIBG. Por lo demás, una tal prohibición sería contradictoria con la causa de inadmisión referida a información que esté en curso de elaboración -art. 18.1.a)-, y con el límite relativo a la garantía de la confidencialidad o el secreto requerido en procesos de toma de decisión -art. 14.1.k)-, los cuales serían por completo superfluos en caso de limitar el acceso a la información relativa a procedimientos terminados ${ }^{29}$.

\footnotetext{
${ }^{28}$ De otra opinión D. CANALS AMETLER (2016: 35), quien considera que no se permite el acceso a procedimientos no finalizados.

${ }^{29}$ Así, la GAIP a partir de la Resolución de 23 de diciembre de 2015, sobre la Reclamación 17/2015: «No hay ninguna disposición en la LTAIPBG, incluida su disposición adicional 1a, que establezca ningún motivo de inadmisión, ni ningún límite de acceso que se definan en función del carácter abierto o cerrado de los procedimientos administrativos. Esto conlleva que el derecho de acceso a la información pública debe poder ejercerse con independencia de si esta información forma parte de un procedimiento abierto o cerrado, o de ningún procedimiento específico. Si la voluntad del legislador fuera la de denegar el acceso a los expedientes cerrados, ya lo habría establecido, y no lo hace, ni por activa, ni por pasiva. Más bien todo el contrario: la Exposición de motivos de la Ley estatal 19/2013, de 9 de diciembre, de transparencia, acceso a la información pública y buen gobierno, que tiene una disposición adicional 1a con el mismo contenido de la disposición adicional 1a de la LTAIPBG, señala expresamente como una de las limitaciones de la regulación precedente del
} 
De todo lo anterior se infiere que la circunstancia según la cual la información objeto de solicitud se refiera a un procedimiento en curso o terminado no constituye ya una limitación para el acceso a la información por parte de terceros, como sucedía con la Ley 30/1992, sino una exigencia para la aplicación del régimen de acceso previsto en la legislación de procedimiento por parte de los interesados. $Y$, por tanto, el derecho de acceso reconocido en la LTAIBG a personas que no tengan la condición de interesados no está condicionado por dicha circunstancia ${ }^{30}$. Cuestión distinta, naturalmente, será el alcance del mismo y, en particular, debido a la protección de datos personales ${ }^{31} . \mathrm{Y}$, naturalmente, la petición de información no convierte a los solicitantes en interesados en el procedimiento en cuestión, en el cual no podrán participar ${ }^{32}$.

Esta es sin duda la interpretación que se infiere de la aplicación conjunta de la LTAIBG y de la LPAC. Ahora bien, alguien podrá preguntarse si no supone este acceso abierto a cualquiera a un procedimiento en curso un riesgo a la eficacia de la actuación administrativa. De entrada, debe advertirse que este derecho era ya ejercitable en relación con la información pública ambiental desde la Ley 38/1995. sin que conste que se haya producido una lesión a la eficacia de la Administración.

derecho de acceso, que precisamente pretende superar la nueva legislación de transparencia, el hecho de limitar el acceso a los documentos contenidos a procedimientos administrativos ya finalizados (apartado II de la Exposición de motivos, en relación con el artículo 37 Ley 30/1992). Está claro, pues, que la voluntad del legislador no puede ser otra que la de admitir y proteger el ejercicio del derecho de acceso, por parte de cualquier persona, a la información pública, con independencia del carácter abierto o cerrado de los procedimientos que la contienen». Igualmente, el Consejo de Transparencia de Aragón ha declarado de modo constante que los documentos de procedimientos en curso constituyen información pública a los efectos de la normativa de transparencia y son, por tanto, susceptibles de ser consultados en ejercicio del derecho general de acceso reconocido por estas leyes (p. ej., Resolución 14/2020, de 15 de junio).

30 Así, GAIP, Dictamen núm. 1/2017. Consulta general sobre l'accés als expedients sancionadors en materia de medi ambient, se dirá: «la legislació de transparència no distingeix en cap dels seus preceptes eventuals continguts diferents del dret d'accés segons si s'exerceix en relació amb expedients oberts o tancats». Igualmente, GAIP, Resolución 303/2017, de 8 de septiembre; Resolución 247/2020, de 9 de abril. En este sentido, de modo incidental, el Consejo de Transparencia de Comunidad Valenciana, resolución $n^{\circ} 2$ de 26-4-2016, reclamación n 6/2015; así como Res. exp. 12/2016, 10-3-2017. También en este sentido, el Consejo de Transparencia de Aragón (Resolución 23/2017, de 18 de septiembre) ha señalado que los documentos de procedimientos en curso constituyen información pública a los efectos de la normativa de transparencia y son, por tanto, susceptibles de ser consultados en ejercicio del derecho general de acceso reconocido por estas leyes.

${ }^{31}$ Así, Informe 2/2020, 15 de junio, del Consejo de Transparencia de Aragón, emitido a solicitud del Instituto Aragonés de Administración Pública, relativo a la transparencia de las actas de los Tribunales calificadores y de los exámenes en los procesos selectivos: «el hecho de que el procedimiento o procedimientos selectivos no hayan finalizado en el momento en el que se solicita la información no constituye, por sí mismo, motivo legal para denegar el acceso a la información que se contiene en los expedientes en los que se sustancian los procedimientos de selección de personal, tanto a las personas interesadas como a las no interesadas, a excepción, claro está, de aquella información cuya divulgación suponga un perjuicio para los principios establecidos por la legislación vigente para el acceso al sector público». Sobre los límites aplicables a terceros, véase O. MIR PUIGPELAT (2019: 130131).

32 Así, O. MIR PUIGPELAT (2017: 58) señala que el acceso a procedimientos en curso no implica reconocer, por supuesto, la condición de interesado a quienes lo soliciten, ni permitirles participar en los mismos ni impugnar la resolución que les ponga fin. 
Pero, sobre todo, como señala MIR PUIGPELAT, este acceso por parte de la ciudadanía a procedimientos administrativos en curso debe valorarse positivamente pues, entre otros motivos, refuerza la función de control del derecho de acceso antes de la adopción de una decisión lesiva para los intereses públicos, sobre todo en procedimientos administrativos complejos que requieren de una tramitación dilatada en el tiempo ${ }^{33}$.

Finalmente, todo ello obliga, en nuestra opinión, a entender derogado el artículo 3 del Real Decreto 208/1996, de 9 de febrero, antes reproducido ${ }^{34}$. Asimismo, entendemos que tampoco se adecua a los parámetros de la LTAIBG la disposición de la Ley 4/2013 Extremadura según la cual «tendrán la consideración de información pública de libre acceso para cualquier ciudadano, sin que precise ostentar la condición de interesado, los expedientes administrativos que estén concluidos»-art. 15.3-, pues parecería inferirse que carece de la condición de información pública la relativa a expedientes en curso, lo cual supone una clara vulneración del artículo 13 de la LTAIBG ${ }^{35}$. Asimismo, se aprecian ya disposiciones orientadas a resucitar la exigencia de terminación del procedimiento, lo cual estimamos que supone (re)construir un límite no contemplado en la Ley ${ }^{36}$.

\title{
4.3. ¿Acceso por parte de interesados conforme a la LTAIBG?
}

Una vez establecido que los terceros pueden hacer uso del derecho de acceso conforme a la LTAIBG, se plantea la cuestión de si pueden también ejercer este

\footnotetext{
33 O. MIR PUIGPELAT (2019: 42-44), quien apunta otros beneficios, como la mejora de la participación ciudadana en los trámites de información pública.
}

\begin{abstract}
${ }^{34}$ Además, es muy cuestionable que «la identificación de las autoridades y personal al servicio de la Administración General del Estado y de las entidades de derecho público vinculado o dependiente de la misma bajo cuya responsabilidad se tramiten aquellos procedimientos», pueda seguir calificándose de información «particular», pues forma parte de la información de obligatoria publicidad activa.

${ }^{35}$ La Ley extremeña añade lo siguiente: «No obstante, en este caso, a diferencia de lo establecido en el apartado dos anterior, esta información no será publicada de oficio por la propia Administración, sino que deberá mediar solicitud previa para ello, y su acceso se producirá de conformidad con lo establecido en esta ley, en el marco de los principios generales del procedimiento administrativo común y con respeto a la normativa de protección de datos personales». En este sentido, se expresaba el caducado Proyecto de Ley de Transparencia, Participación Ciudadana y Buen Gobierno del Sector Público del País Vasco, admitido a trámite en el Parlamento vasco el 17 de septiembre de 2015 (10/09.01.00.0018). También tendrán la consideración de información pública de libre acceso para cualquier ciudadano o ciudadana, sin que precise ostentar la condición de persona interesada, los expedientes administrativos que estén concluidos o (añadia), en su caso, los trámites concluidos de los expedientes administrativos -art. 34-.
\end{abstract}

${ }^{36}$ Por ejemplo, el Real Decreto 182/2015, de 13 de marzo, por el que se aprueba el Reglamento de procedimiento del régimen sancionador en materia de pesca marítima en aguas exteriores, tras declarar retóricamente que el procedimiento sancionador en materia de pesca marítima se desarrollará de acuerdo con el principio de transparencia del procedimiento, y reconocer (innecesariamente) que los interesados tienen derecho a conocer su estado de tramitación y a acceder y obtener copias de los documentos contenidos en el mismo, añade lo siguiente: «El acceso a los documentos que obren en los expedientes sancionadores ya concluidos se regirá por lo dispuesto en el artículo 37 de la Ley 30/1992, de 26 de noviembre»-art. 4.3-. De entrada, llama la atención la remisión al art. 37 Ley 30/1992, cuando ya estaba en vigor para el Estado la Ley 19/2013, pero sobre todo es clara la intencionalidad de mantener el acceso ciudadano a expedientes ya concluidos. 
derecho los propios interesados en el procedimiento. Evidentemente, esta cuestión carecía de sentido en la Ley 30/1992, pues se trataba de la misma Ley, pero sí presenta un gran interés en la actualidad, sobre todo, en relación con la posibilidad de hacer uso de la reclamación especial ante el órgano de garantía.

A este respecto, el CTBG y algunos órganos independientes (como el Consejo de Transparencia y Protección de Datos de Andalucía, el Comisión de Transparencia de Galicia o el Comisionado de Transparencia y Acceso a la Información Pública de Canarias) consideran que de la DA $1^{\text {a }}$, y su remisión a la normativa reguladora del procedimiento administrativo, se desprende que no es de aplicación en estos casos la garantía pre-contenciosa de la LTAIBG $^{37}$. Y así lo han entendido algunos órganos jurisdiccionales, según los cuales los interesados en el procedimiento no pueden hacer uso del derecho de acceso de la LTAIBG mientras ése se sustancie ${ }^{38}$. Asimismo, alguna disposición reglamentaria se pronuncia también expresamente en este sentido ${ }^{39}$.

No obstante, algunos órganos autonómicos (GAIP, Comisión de Transparencia de Castilla y León, Consejos de Transparencia de Aragón y Comunidad Valenciana) se han manifestado partidarios de reconocer a los interesados en un procedimiento en curso la posibilidad de acudir a la reclamación ante dicha institución. Así, según la GAIP, si las personas que no tienen la condición de interesados pueden solicitar acceder a la información relativa a un procedimiento en curso $\mathrm{y}$, en su caso, reclamar ante el órgano independiente, con mayor motivo han de poder hacerlo los interesados, que gozan de un derecho de acceso al expediente reforzado por su derecho a la defensa: «Establecido el derecho de cualquier persona a acceder a la documentación incluida a procedimientos administrativos abiertos, debe valorarse acto seguido si este derecho se puede restringir cuando quién lo ejerce tiene la condición de persona interesada en el procedimiento administrativo concernido. Por razones de mera obviedad debe descartarse esta posibilidad, ya

${ }^{37}$ CTBG, Resoluciones R/0006/2015, de 19 de febrero; R/0025/2015, de 17 de abril; R/0110/2016, de 14 de junio; R/0111/2016, de 15 de junio; y RT/0176/2016, de 5 de octubre, R/0406/2016; $\mathrm{R} / 0407 / 2016$, de 12 de diciembre, entre otras. En el mismo sentido, Consejo de Transparencia y Protección de Datos de Andalucia, RES/104/2016, de 16 de noviembre y RES/118/2016, de 7 de diciembre; Comisionado de Transparencia y Acceso a la Información Pública de Canarias, R30/2016; Comisión de Transparencia de Galicia, Resoluciones 50/2018 y 78/2018, así como Consulta 1/2018.

\footnotetext{
${ }^{38}$ Así, p. ej., Juzgado Central C-A n 12, sentencia 61/2019, de 5 de abril, rec. 66/2017: «lo cierto es que pedir copia de un expediente iniciado por uno mismo y todavía no concluido por no haberse dictado resolución no supone ejercer derechos derivados de la LAITBG, por mucho de que se cite esta norma. Esa solicitud supone hacer uso de uno de los derechos que tienen los interesados en los procedimientos administrativos».

39 En este sentido la Ordenanza de Transparencia de la Ciudad de Madrid de 27 de julio de 2016 declara expresamente que no se aplicará este régimen cuando exista una regulación especial del derecho de acceso o cuando el solicitante quiera acceder a los documentos que obran en un procedimiento en curso en el que ostente la condición de interesado -art. 20.2-. Asimismo, el Anteproyecto Reglamento de la LTAIBG de 2015 disponía lo siguiente: «Cuando un interesado presente una solicitud que tenga por objeto el acceso a documentos que formen parte de un procedimiento administrativo en curso se aplicarán las normas reguladoras de dicho procedimiento» (art. 13).
}

Revista Española de la Transparencia. RET. ISSN 2444-2607

Núm. 12. Primer Semestre. Enero-Junio de 2021, pp. 25-46

DOI: https://doi.org/10.51915/ret.134 
que sería una auténtica incongruencia, contraria a los más elementales principios de igualdad y de no discriminación, ofrecer mayor acceso y mejor garantizado a la información pública contenida en un procedimiento abierto a la ciudadanía en general, que a las personas que tienen la condición de interesadas. Cabe tener en cuenta, además, que no hay ningún precepto en la LTAIPBG del que se pueda desprender que la condición de interesado o interesada en un procedimiento administrativo deba ser o pueda ser un motivo de inadmisión de las solicitudes de información a la Administración pública o de las reclamaciones a la GAIP» ${ }^{40}$.

En este sentido, el CTCYL ha declarado que «resulta innegable que un interesado en un procedimiento administrativo no puede tener menos derechos respecto al acceso a la información relacionada con el mismo que cualquier otro ciudadano que no reúna tal condición; en otras palabras, puesto que la información relativa a un procedimiento administrativo es información pública, los interesados en el mismo tendrán, cuando menos, las mismas posibilidades de acceder a tal información que el resto de ciudadanos al amparo de lo previsto en la LTAIBG, incluidas las de impugnación de las decisiones administrativas que se adopten al respecto» ${ }^{41}$.

En estos casos, la GAIP aplica preferentemente la regulación del derecho de acceso al expediente de los interesados propia de la normativa de procedimiento administrativo, que a su vez remite a la legislación de transparencia en cuanto a los límites del acceso (artículos 13.d, 27.4, 53.a y 82.1 LPAC) ${ }^{42}$. La reclamación ante la

40 GAIP, Resolución de 23 de diciembre de 2015, sobre la Reclamación 17/2015, que añade: «Por lo tanto, la consecuencia de si se diera la circunstancia de la disposición adicional 1.a LTAIPBG sería básicamente que tanto la Administración como la GAIP tendrían que reconocer a las personas interesadas en el procedimiento administrativo (tanto en el momento de atender sus solicitudes de información, como en el de resolver sus reclamaciones o sus recursos) el plus de legitimidad que pueda corresponder a esta condición, con respecto a la predicable a la ciudadanía en general, a los efectos de poder ponderar más favorablemente, si procede, su derecho de acceso con los otros derechos o intereses que concurran en el caso». Igualmente, GAIP, Resoluciones 19/2015, 24/2015, 7/2016, 176/2016 (sobre licitadores en un procedimiento de adjudicación de contratos), 162/2017 y 92/2018 (sobre el inculpado en un procedimiento sancionador), Resolución 247/2020, de 9 de abril. De modo general, la GAIP considera que la legislación de transparencia reconoce un derecho universal de acceso a la información pública, que pueden ejercer tanto las personas interesadas, como las no interesadas en un procedimiento administrativo, que puede tener por objeto tanto la información pública integrada en un procedimiento abierto o en trámite, como la que forma parte de un procedimiento cerrado o acabado, o la no incluida en un procedimiento determinado. GAIP, Dictamen 1/2016, FJ 1.

${ }^{41}$ Comisión de Transparencia de Castilla y León, Resolución 24/2016, de 8 de agosto. Y, en el mismo sentido, Comisión de Transparencia de Castilla y León, Resolución 46/2016, de 11 de noviembre; Resolución Comisión de Transparencia de Castilla y León 70/2017, de 14 de julio. Por su parte, el Consejo de Transparencia de la Comunidad Valenciana (Res. exp. 12/2016, 10-3-2017) ha señalado: «si el interesado en un procedimiento solicita la información al amparo de la legislación y garantías del derecho de acceso a la información» contará con el régimen de la Ley 19/2013 además de un régimen privilegiado por cuanto «que la posición jurídica de interesado favorecerá las posibilidades de acceso a la información.» «si el interesado en un procedimiento solicita la información al amparo de la legislación y garantías del derecho de acceso a la información» contará con el régimen de la Ley 19/2013 además de un régimen privilegiado por cuanto «que la posición juridica de interesado favorecerá las posibilidades de acceso a la información».

42 El Consejo de Transparencia de la Comunidad Valenciana (Informe 5/2017 de 29-06-2017 sobre la condición de interesados en un expediente administrativo en respuesta a una consulta) ha aclarado 
GAIP no suspende el procedimiento en cuestión ni los plazos previstos para la impugnación de sus actos de trámite y de la resolución que le ponga fin, y tiene solo por finalidad determinar si la persona reclamante tiene o no derecho de acceso a la información o expediente solicitado, sin que la GAIP disponga de competencia para pronunciarse sobre las cuestiones que constituyen el objeto principal de aquel procedimiento ${ }^{43}$.

Por su parte, de modo más matizado, el CTAR considera que si un interesado formula una solicitud de derecho de acceso fundamentada en la normativa de transparencia mientras el procedimiento está «en curso» debe inadmitirse esa solicitud, en aplicación de la D. A. $1^{\text {a }}$ de la Ley 19/2013, y resolverse por la normativa que rija el procedimiento (Ley 39/2015), pero esto «no significa no aplicar los principios y criterios propios de la transparencia, pues lo contrario supondría que, en relación con un mismo objeto, se otorgue mejor acceso a una persona no interesada, aplicando la normativa de transparencia, que a una persona interesada, aplicando la legislación de procedimiento administrativo», y admitiendo la posibilidad de plantear una reclamación ante el órgano de garantía ${ }^{44}$.

En mi opinión, si bien podría pensarse que el acceso vía LTAIBG es innecesario, al disponer el interesado del acceso contemplado en la legislación de procedimiento, debido a las indicadas insuficiencias de la LPAC, bien podria suceder que a una persona que tenga la condición de interesada en un concreto procedimiento le fuese más ventajoso ejercer el derecho de acceso de la LTAIBG y la reclamación prevista en la LTAIBG ante el CTBG u órgano independiente autonómico, para no llegar al absurdo de que el interesado esté en peor condición que el tercero ${ }^{45}$. Sin embargo, no se puede pasar por alto que, a diferencia de los regímenes especiales de acceso a la información previstos en los apartados $2^{\circ}$ y $3^{\circ}$ de la DA $1^{\text {a }}$ LTAIBG, en este caso

que si un interesado ejerce el derecho de acceso al expediente [art. 53.1.a) Ley 39/2015], la Administración no está obligada a dar traslado para alegaciones a los posibles afectados en sus intereses en razón del artículo 19.3 Ley 19/2013 (y artículo 15.5 Ley 2/2015), en tanto en cuanto la normativa administrativa de acceso al expediente no lo regula. Cuestión diferente es que, si hay una reclamación ante el Consejo de Transparencia de la Comunidad Valenciana, en virtud del artículo 24.3 Ley 19/2013 el Consejo sí que deba proceder a este trámite de alegaciones.

${ }^{43}$ GAIP, Resolución 21/2017, de 1 de febrero.

${ }^{44}$ Consejo de Transparencia de Aragón, Resolución 5/2018, de 5 de febrero, o Resolución 17/2018, de 16 de abril; Resolución 14/2020, de 15 de junio. Y de modo más completo, Informe 2/2020, 15 de junio, del Consejo de Transparencia de Aragón, emitido a solicitud del Instituto Aragonés de Administración Pública, relativo a la transparencia de las actas de los Tribunales calificadores y de los exámenes en los procesos selectivos.

45 S. FERNÁNDEZ RAMOS - J. Ma PÉREZ MONGUIÓ (2014: 53); L. RAMS RAMOS (2015: 645); L. RAMS RAMOS (2016: 13); D. CANALS AMETLER (2016: 35). Así, E. GUICHOT (2014: 49), expresa: «Parece que, en todo caso, nunca podría ser de peor condición el acceso por el interesado que el acceso por terceros y que los derechos de contradicción y defensa deberian conllevar una inaplicación o una aplicación más reducida de los valores protegidos por algunos de los límites contemplados en el art. 14 LTBG como los relativos a la prevención, investigación y sanción de los ilícitos penales, administrativos o disciplinarios, las funciones administrativas de vigilancia, inspección y control, la garantía de la confidencialidad o el secreto requerido en procesos de toma de decisión». Aparentemente de otra opinión, C. BARRERO RODRÍGUEZ (2014: 212; 2015b: 75, nota 43). 
el apartado $1^{\circ}$ no contempla la aplicación supletoria de la LTAIBG, lo cual supone, entiendo, un serio obstáculo a su aplicación ${ }^{46}$. Con todo, al menos en lo que se refiere a la reclamación, ello supone únicamente aplazar la presentación de la reclamación a la terminación del procedimiento, pues en tal caso ya no será -como nos consta- de aplicación el apartado 1 de la DA $1^{\text {a }}$ LTAIBG $^{47}$.

\footnotetext{
${ }^{46}$ A este respecto, el Consejo de Transparencia y Protección de Datos de Andalucía (2018: 131) ha señalado lo siguiente: «El CTPD Andalucia es conocedor de que algún otro órgano de garantía no considera de aplicación este criterio a quien resulta interesado, con base en que no puede quedar en peor situación un interesado que un tercero que pretenda el acceso. Sin embargo, una aplicación literal de la LTPA (lege data) conduce directamente a que el Consejo la aplique, y entendemos que constituyen cuestiones lege ferenda la razón o "justicia" consistente en que el interesado y el tercero no tengan el mismo derecho.

${ }^{47}$ Este es realmente el caso de la STSJ Castilla y León (Valladolid) 1253/2019, de 24 de octubre, en la que se indica: «se ha de entender que entre las dos posturas enfrentadas, presentes respectivamente en el criterio del Consejo de Transparencia y Buen Gobierno de la Administración Central del Estado, y el de diversos Consejos de la Administraciones autonómicas -se han citado en la resolución recurrida los de Aragón, Valencia y Cataluña- hemos de reputar como más adecuada la que se ha recogido en la reiterada resolución recurrida, y que es, asimismo, aceptada por la sentencia apelada. Ello es asi, esencialmente, por la consideración de que el carácter de interesado, no puede hacer acreedor de menores derechos a quien ostenta tal carácter, que a cualquier ciudadano que con carácter general puede ejercitar dicho derecho de información, por lo que con mayor razón ha de poder hacerlo quien ostenta unos intereses específicos o incluso derechos en relación con las pretensiones que se dilucidan en un procedimiento».
} 


\section{Bibliografía}

BARRERO RODRÍGUEZ, Concepción (2014): «El derecho de acceso a la información: publicidad pasiva», en VV AA, Transparencia, acceso a la información pública y Buen Gobierno, Estudio de la Ley 19/2013, de 9 de diciembre, Ed. Tecnos, Madrid, pp. 199-246.

CANALS AMETLER, Dolors (2016): «El acceso público a datos en un contexto de transparencia y buena regulación», en Datos, protección, transparencia y buena regulación, Documenta Universitaria, Girona, pp. 11 y ss.

Consejo de Transparencia y Protección de Datos de Andalucía (2018), «Informe del Consejo de Transparencia y Protección de Datos de Andalucía», Anuario de Transparencia Local, pp. 125-164.

FERNÁNDEZ RAMOS, Severiano (1997): El derecho de acceso a los documentos administrativos, Marcial Pons, Madrid.

FERNÁNDEZ RAMOS, S. - PÉREZ MONGUIÓ, J. Ma (2014): Transparencia, Acceso a la Información Pública y Buen Gobierno, Aranzadi-Thomson, Cizur Menor.

GUICHOT, Emilio (2017): «Derecho de acceso a la información pública», en Tratado de procedimiento administrativo común y régimen juridico básico del sector Público, I Tomo, Tirant lo Blanch, Valencia, 533-580.

-(2014): «La aplicación de la Ley Andaluza de transparencia en las entidades locales», Revista Andaluza de Administración Pública, núm. 90, pp. 15-55.

MIR PUIGPELAT, Oriol (2019): Transparencia y procedimiento administrativo. El derecho de acceso al expediente y su conexión con el derecho de acceso a la información pública, Civitas, Thomson Reuters, Cizur Menor.

-(2017): «El acceso a la información pública en la legislación española de transparencia: crónica de un cambio de paradigma». Revista Catalana de Dret Públic, núm. 55 (diciembre 2017), pp. 48-66. 
RAMS RAMOS, Leonor (2016): «El procedimiento de ejercicio del derecho de acceso a la información pública», Revista General de Derecho Administrativo, núm. 41.

-(2015): «Cuestiones problemáticas en el procedimiento de ejercicio del derecho de acceso a la información en la Ley de transparencia, acceso a la información pública y buen gobierno», en Régimen juridico básico de las Administraciones Públicas, Libro homenaje a Luis Cosculluela, lustel, Madrid, pp. 639 y ss. 